\title{
Distribution of central blood pressure values estimated by Omron HEM-9000Al in the Japanese general population
}

\author{
Hiroyuki Takase ${ }^{1}$, Yasuaki Dohi ${ }^{2}$ and Genjiro Kimura ${ }^{2}$
}

Central blood pressure is more closely associated with cardiovascular events and target organ damage than peripheral blood pressure measured over the brachium using a conventional method. This study was designed to investigate the distribution of central systolic blood pressure values estimated by Omron HEM-9000Al in the Japanese general population. A cross-sectional study were performed in 10756 subjects without overt cardiovascular disease (male $=6574$; mean age $55.3 \pm 12.5$ years, range 20-91 years). Of these, 7348 subjects received no antihypertensive, antidiabetic or lipid-lowering drug treatment, and were used for the present analysis. Estimated central systolic blood pressure was higher than brachial systolic blood pressure and was significantly correlated with age and brachial blood pressure. The central systolic blood pressure values obtained from subjects without cardiovascular risk factors other than hypertension were $125.8 \pm 37.2$ (mean \pm 2 s.d., $n=3760$ ) $\mathrm{mm} \mathrm{Hg}$. The values obtained from subjects with no cardiovascular risk factors were $112.6 \pm 19.2(n=1975) \mathrm{mm} \mathrm{Hg}$ for optimal and $129.2 \pm 14.9 \mathrm{~mm} \mathrm{Hg}$ for normal brachial blood pressure categories $(n=697)$. This study is the first to show the distribution of central systolic blood pressure values estimated using the Omron HEM-9000Al, marking an important step toward implementing the clinical use of central blood pressure in the diagnosis and management of hypertension. Hypertension Research (2013) 36, 50-57; doi:10.1038/hr.2012.122; published online 16 August 2012

Keywords: arterial stiffness; cardiovascular risk; pressure waveform; tonometer

\section{INTRODUCTION}

Several guidelines include a blood pressure (BP) category to define arterial hypertension. ${ }^{1-3} \mathrm{BP}$ measured over the brachial artery is usually used for patient evaluation and management, based on its role as a powerful predictor of cardiovascular morbidity and mortality. ${ }^{1-6}$ Recent studies have suggested that central BP is more closely associated with cardiovascular events and target organ damage than brachial $\mathrm{BP},{ }^{7-11}$ although this idea is still controversial. ${ }^{12,13}$ In spite of its emergence as the better index for cardiovascular risk management, a wider implementation of central BP into clinical practice is hampered by the lack of established reference values.

The superiority of central BP over brachial BP in monitoring therapeutic effects and predicting cardiovascular events has been well established using the SphygmoCor technique (AtCor Medical, Sydney, Australia).7,9,14,15 The SphygmoCor device directly records radial pulse waveform by tonometry, and this is converted to a central aortic pressure waveform using a generalized transfer function. Central BP is then estimated by calibration against brachial BP. ${ }^{16,17}$ Recently, an automated device for the estimation of central systolic BP has been introduced, namely the Omron HEM-9000AI
(Omron Healthcare, Kyoto, Japan). ${ }^{18-22}$ The Omron device records radial pulse waveform in an automated manner, and BP corresponding to the second systolic peak is obtained by calibration against brachial BP. The central systolic BP is then estimated using a regression equation. ${ }^{18,22}$ Because of the simplicity of these measurements, ${ }^{18,22}$ use of the Omron device is now widespread especially in Japan. These noninvasive estimations show close correlation with the invasive measurements of central BP in ascending aorta. ${ }^{18,21,22}$ Furthermore, central systolic BP values estimated by the Omron device are highly correlated with those estimated on a SphygmoCor device. ${ }^{19-21}$ However, both devices underestimate central systolic BP, with the SphygmoCor device producing a larger deviation (average, $-15 \mathrm{~mm} \mathrm{Hg}$ ) than the Omron device $(-2 \mathrm{~mm} \mathrm{Hg}){ }^{21}$ These results indicated that central systolic BP estimated by either the Omron or SphygmoCor device could provide a useful clinical marker in the management of hypertension, although the Omron device apparently requires its own reference values because of technological differences between the systems. Thus, this study was designed to investigate the distribution of central systolic BP values estimated by the Omron device in the Japanese general population.

${ }^{1}$ Department of Internal Medicine, Enshu Hospital, Hamamatsu, Japan and ${ }^{2}$ Department of Cardio-Renal Medicine and Hypertension, Nagoya City University Graduate School of Medical Sciences, Nagoya, Japan

Correspondence: Dr Y Dohi, Department of Cardio-Renal Medicine and Hypertension, Nagoya City University Graduate School of Medical Sciences, Mizuho-ku, Nagoya 467-8601, Japan.

E-mail: ydohi@med.nagoya-cu.ac.jp

Received 30 March 2012; revised 19 June 2012; accepted 22 June 2012; published online 16 August 2012 


\section{METHODS}

Study design and subjects

A cross-sectional study was used to evaluate characteristics relevant to central BP in subjects with various cardiovascular risk factors. We enrolled 10756 consecutive subjects aged 20 years or more (male $=6574$; mean age $55.3 \pm 12.5$ years, range 20-91 years), who underwent a multiphasic health checkup in the Department of Health Checkup, Enshu Hospital, from January 2009 to September 2011. Subjects with overt cardiovascular disease were excluded from the study. We undertook this study in accordance with the principles of the Declaration of Helsinki. The study protocol was approved by the Ethics Committee of Enshu Hospital. All patients gave written informed consent to participate before the start of the study.

\section{Study procedures}

Our health checkup program included a routine physical examination, chest $\mathrm{X}$-ray, electrocardiography and laboratory assessment of cardiovascular risk factors. Brachial BP (oscillometer) was measured and central systolic BP was estimated after participants were seated in a chair for $5 \mathrm{~min}$ with their backs supported and their arms supported at heart level in an air-conditioned room (HEM-9000AI; Omron Healthcare).

The population was categorized according to age decade $(20-29,30-39,40-$ $49,50-59,60-69$ and $\geqslant 70$ years) and BP category. To investigate the distribution of central systolic BP values, subjects were excluded if taking medications that may affect BP or arterial stiffness, which is an important determinant of central BP (Figure 1). 'Population A' was defined as subjects of both sexes taking no medication for hypertension, dyslipidemia or diabetes mellitus. Subjects with major risk factors were then excluded from 'population A' to form a near-normal population. 'Population B' was defined as subjects of both sexes without major cardiovascular risk factors other than hypertension (without diabetes, dyslipidemia or current smoking) and not taking antihypertensive medication. 'Population C' was defined as subjects with optimal or normal BP and no major cardiovascular risk factors (Figure 1). Classification of brachial BP levels was defined as follows: optimal BP, systolic BP $<120 \mathrm{~mm} \mathrm{Hg}$ and diastolic BP $<80 \mathrm{~mm} \mathrm{Hg}$; normal BP, systolic BP $<130$ $\mathrm{mm} \mathrm{Hg}$ and diastolic BP $<85 \mathrm{~mm} \mathrm{Hg}$; high normal BP, systolic BP 130 $139 \mathrm{~mm} \mathrm{Hg}$ and/or diastolic BP $85-89 \mathrm{~mm} \mathrm{Hg}$; hypertension, systolic BP $\geqslant 140 \mathrm{~mm} \mathrm{Hg}$ and/or diastolic BP $\geqslant 90 \mathrm{~mm} \mathrm{Hg} .^{1-3}$ Subjects taking antihypertensive medications were classified as hypertension. In this study, diabetes mellitus was defined by a fasting plasma glucose $\geqslant 126 \mathrm{mg} \mathrm{dl}^{-1}$ or by the use of antidiabetic medications, whereas dyslipidemia was defined by lowdensity lipoprotein cholesterol levels $\geqslant 140 \mathrm{mg} \mathrm{dl}^{-1}$, high-density lipoprotein cholesterol values $<40 \mathrm{mg} \mathrm{dl}^{-1}$, triglycerides $\geqslant 150 \mathrm{mg} \mathrm{dl}^{-1}$ or the use of antidyslipidemic medications. The estimated glomerular filtration rate was calculated using the Japanese Society of Nephrology formula. ${ }^{23}$

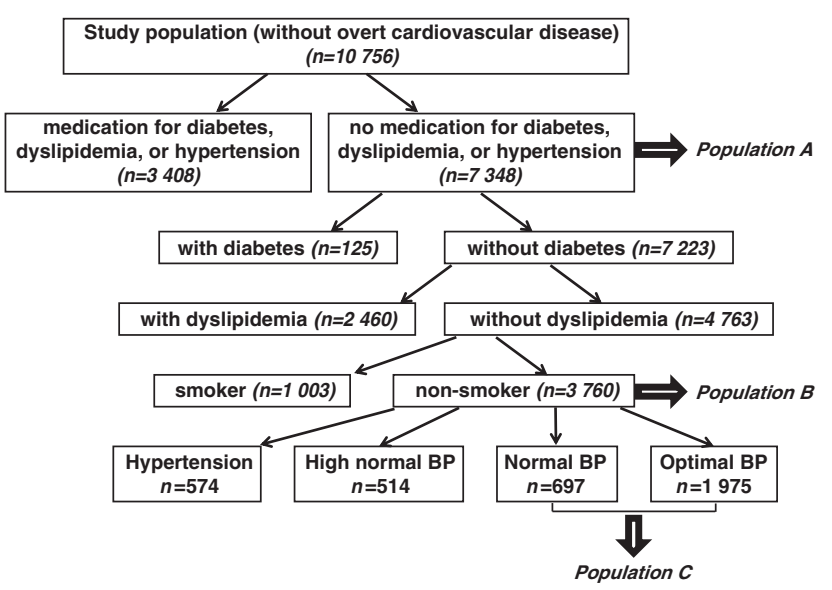

Figure 1 Flowchart describing the methods for selection of subjects included in populations A-C. BP, blood pressure.

\section{Estimation of central BP}

Radial artery pressure waveforms and brachial BP were recorded simultaneously using a fully automated device (HEM-9000AI; Omron Healthcare) to calculate late systolic pressure in the radial artery (SBP2) and estimate central systolic BP. The brachial BP was measured with an oscillometric manometer and the radial pulse waveforms were recorded noninvasively using an applanation tonometer, which consisted of a sensor unit with an array of 40 fine-pitch microtransducer elements and a monitor unit. As one of these 40 sensor elements is automatically selected to obtain the optimal radial arterial pressure waveform, this method is considered to provide better objectivity. Signals of the radial arterial pressure wave were low-pass filtered: first at a cutoff frequency of $105 \mathrm{~Hz}$ to remove high-frequency noise, and second at $25 \mathrm{~Hz}$ to extract pressure waveforms. The radial arterial waveform obtained with this device is reportedly identical to the simultaneously and invasively measured intra-arterial pulse waveform of the opposite radial artery. ${ }^{18}$

Inflection points or peaks that corresponded to early and late systolic BP were obtained by multidimensional derivatives of the original pulse pressure waveforms. The maximal systolic pressure and diastolic pressure in the radial artery were calibrated with the brachial systolic BP and diastolic BP, respectively. The late systolic BP in the radial artery (SBP2) was calculated by the following equation:

$$
\mathrm{SBP} 2=(\mathrm{P} 2 / \mathrm{PP}) \times(\text { systolic } \mathrm{BP}-\text { diastolic } \mathrm{BP})+\text { diastolic } \mathrm{BP},
$$

where P2 and PP indicate the height of the late systolic shoulder/peak pressure and the pulse pressure of the radial arterial pressure contour, respectively. Central systolic BP was estimated using a regression equation with SBP2 as a major independent variable. ${ }^{18,22}$ Subjects who showed arrhythmia during this procedure were excluded from this study.

\section{Statistics}

All analyses were performed using StatView 5.0 (SAS Institute, Cary, NC, USA). Data in the text and the tables are expressed as mean \pm s.d. unless otherwise stated. Differences between two means that had a normal distribution were compared by unpaired Student's $t$-test or analysis of variance followed by Scheffe's F-test. A $P$-value of $<0.05$ was considered statistically significant.

\section{RESULTS}

The baseline characteristics of study subjects are listed in Table 1. Although subjects with overt cardiovascular disease were excluded from this study, the majority of study subjects $(n=7570,70.4 \%)$ had at least one of the following cardiovascular risk factors: hypertension, diabetes mellitus, dyslipidemia or a smoking habit. Among 3758 subjects with hypertension, 2040 subjects (54.3\%) were taking antihypertensive medication. Similarly, $83.7 \%$ and $28.6 \%$ of subjects with diabetes and dyslipidemia, respectively, were taking medications. Table 2 presents the characteristics of populations A, B and C. BP was lower in population $\mathrm{B}$ than in population $\mathrm{A}$, and lower still in population C. Similarly, the mean age was lowest in population $\mathrm{C}$ (Table 2).

Brachial BP increased with age in populations A and B (Figure 2 and Table 3). Such an increase was also observed in population $\mathrm{C}$, although the impact of increasing age on brachial BP was small in subjects without hypertension, and the $\mathrm{BP}$ values were lower in population $\mathrm{C}$ than in population $\mathrm{A}$ or $\mathrm{B}$.

The estimated central systolic BP was affected by various factors according to the univariate analysis (Table 4). Among them, brachial BP and age correlated closely with central systolic BP. A significant linear correlation was observed between central systolic BP and age in this study (Figure 3), although the effect was minimal in subjects without major cardiovascular risk factors (hypertension, diabetes, dyslipidemia or smoking; population C; Figure 3c). Central systolic $\mathrm{BP}$ in each decade was greater than the corresponding brachial systolic BP in subjects aged $\geqslant 30$ years in populations A, B and C, 
Table 1 Characteristics of study subjects

\begin{tabular}{|c|c|c|c|}
\hline Characteristic & $\begin{array}{c}\text { Total } \\
(\mathrm{n}=10756)\end{array}$ & $\begin{array}{c}\text { Female } \\
(\mathrm{n}=4182)\end{array}$ & $\begin{array}{c}\text { Male } \\
(\mathrm{n}=6574)\end{array}$ \\
\hline Age (years) & $55.3 \pm 12.5$ & $54.6 \pm 12.2$ & $55.7 \pm 12.7$ \\
\hline Body height $(\mathrm{cm})$ & $162.5 \pm 8.9$ & $154.8 \pm 6.0$ & $167.4 \pm 6.7$ \\
\hline Body weight (kg) & $60.1 \pm 11.4$ & $52.4 \pm 8.5$ & $64.9 \pm 10.4$ \\
\hline Waist circumference $(\mathrm{cm})$ & $83.3 \pm 8.9$ & $81.1 \pm 9.0$ & $84.7 \pm 8.5$ \\
\hline $\begin{array}{l}\text { Systolic blood pressure } \\
(\mathrm{mm} \mathrm{Hg})\end{array}$ & $125.2 \pm 17.8$ & $120.6 \pm 18.6$ & $128.1 \pm 16.9$ \\
\hline $\begin{array}{l}\text { Diastolic blood pressure } \\
(\mathrm{mm} \mathrm{Hg})\end{array}$ & $76.4 \pm 11.9$ & $72.8 \pm 11.6$ & $78.7 \pm 11.4$ \\
\hline Heart rate (b.p.m.) & $63.9 \pm 12.4$ & $64.6 \pm 12.7$ & $63.4 \pm 12.3$ \\
\hline eGFR & $78.0 \pm 14.8$ & $79.3 \pm 15.0$ & $77.1 \pm 14.5$ \\
\hline Uric acid (mg dl $\left.{ }^{-1}\right)$ & $5.4 \pm 1.4$ & $4.4 \pm 1.0$ & $6.0 \pm 1.3$ \\
\hline $\begin{array}{l}\text { Fasting plasma glucose } \\
\left(\mathrm{mg} \mathrm{dl}^{-1}\right)\end{array}$ & $96.0 \pm 18.4$ & $92.2 \pm 13.8$ & $98.4 \pm 20.4$ \\
\hline LDL cholesterol (mg dl-1) & $118.8 \pm 27.5$ & $118.3 \pm 27.9$ & $119.1 \pm 27.3$ \\
\hline HDL cholesterol $\left(\mathrm{mg} \mathrm{dl}^{-1}\right)$ & $58.9 \pm 13.9$ & $64.0 \pm 13.6$ & $55.6 \pm 13.0$ \\
\hline Triglycerides $\left(\mathrm{mg} \mathrm{dl}^{-1}\right)$ & $107.1 \pm 72.7$ & $86.7 \pm 45.1$ & $120.1 \pm 83.2$ \\
\hline Smoking (\%) & 20.9 & 5.7 & 30.7 \\
\hline Hypertension (\%) & 34.9 & 27.4 & 39.8 \\
\hline Diabetes mellitus (\%) & 9.1 & 5.5 & 11.4 \\
\hline Dyslipidemia (\%) & 42.7 & 37.1 & 46.3 \\
\hline
\end{tabular}

Abbreviations: eGFR, estimated glomerular filtration rate; HDL, high-density lipoprotein; LDL, low-density lipoprotein.

Values are mean \pm s.d. or percentage.

Table 2 Characteristics of subjects in populations A-C

\begin{tabular}{|c|c|c|c|}
\hline Characteristic & $\begin{array}{c}\text { Population A } \\
(\mathrm{n}=7348)\end{array}$ & $\begin{array}{c}\text { Population B } \\
(\mathrm{n}=3760)\end{array}$ & $\begin{array}{c}\text { Population C } \\
(\mathrm{n}=2672)\end{array}$ \\
\hline Age (years) & $52.0 \pm 12.1$ & $51.9 \pm 12.5$ & $49.3 \pm 12.0$ \\
\hline Body height $(\mathrm{cm})$ & $163.1 \pm 8.8$ & $161.4 \pm 8.7$ & $161.1 \pm 8.4$ \\
\hline Body weight (kg) & $59.7 \pm 11.3$ & $56.7 \pm 10.3$ & $55.4 \pm 9.8$ \\
\hline $\begin{array}{l}\text { Waist circumference } \\
(\mathrm{cm})\end{array}$ & $82.2 \pm 8.7$ & $80.2 \pm 8.3$ & $79.0 \pm 7.9$ \\
\hline $\begin{array}{l}\text { Systolic blood pressure } \\
(\mathrm{mm} \mathrm{Hg})\end{array}$ & $121.6 \pm 16.8$ & $119.4 \pm 16.6$ & $112.0 \pm 10.0$ \\
\hline $\begin{array}{l}\text { Diastolic blood pressure } \\
(\mathrm{mm} \mathrm{Hg})\end{array}$ & $75.1 \pm 11.7$ & $73.5 \pm 11.4$ & $68.6 \pm 7.9$ \\
\hline Heart rate (b.p.m.) & $63.6 \pm 12.2$ & $63.2 \pm 12.2$ & $62.4 \pm 12.2$ \\
\hline eGFR & $79.7 \pm 14.0$ & $79.6 \pm 14.0$ & $80.3 \pm 13.9$ \\
\hline Uric acid (mg dl-1) & $5.3 \pm 1.4$ & $5.0 \pm 1.3$ & $4.8 \pm 1.3$ \\
\hline $\begin{array}{l}\text { Fasting plasma glucose } \\
\left(\mathrm{mg} \mathrm{dl}^{-1}\right)\end{array}$ & $92.8 \pm 14.8$ & $90.5 \pm 8.4$ & $89.4 \pm 8.0$ \\
\hline $\begin{array}{l}\text { LDL cholesterol } \\
\left(\mathrm{mg} \mathrm{dl}^{-1}\right)\end{array}$ & $119.3 \pm 28.0$ & $107.8 \pm 19.0$ & $106.6 \pm 19.3$ \\
\hline $\begin{array}{l}\text { HDL cholesterol } \\
\left(\mathrm{mg} \mathrm{dl}^{-1}\right)\end{array}$ & $59.4 \pm 14.0$ & $63.9 \pm 13.6$ & $64.4 \pm 13.4$ \\
\hline Triglycerides $\left(\mathrm{mg} \mathrm{dl}^{-1}\right)$ & $103.5 \pm 74.1$ & $74.9 \pm 27.2$ & $71.1 \pm 26.3$ \\
\hline Smoking (\%) & 24.1 & 0 & 0 \\
\hline Hypertension (\%) & 18.1 & 15.3 & 0 \\
\hline Diabetes mellitus (\%) & 1.7 & 0 & 0 \\
\hline Dyslipidemia (\%) & 34.5 & 0 & 0 \\
\hline
\end{tabular}

Abbreviations: eGFR, estimated glomerular filtration rate; HDL, high-density lipoprotein; LDL, low-density lipoprotein; Population A, subjects taking no medication for hypertension, dyslipidemia or diabetes mellitus; Population B, subjects without diabetes, dyslipidemia or current smoking and not taking antihypertensive medication; Population $\mathrm{C}$, subjects with optimal or normal BP and no major cardiovascular risk factors. Values are mean \pm s.d. or percent. a Population A

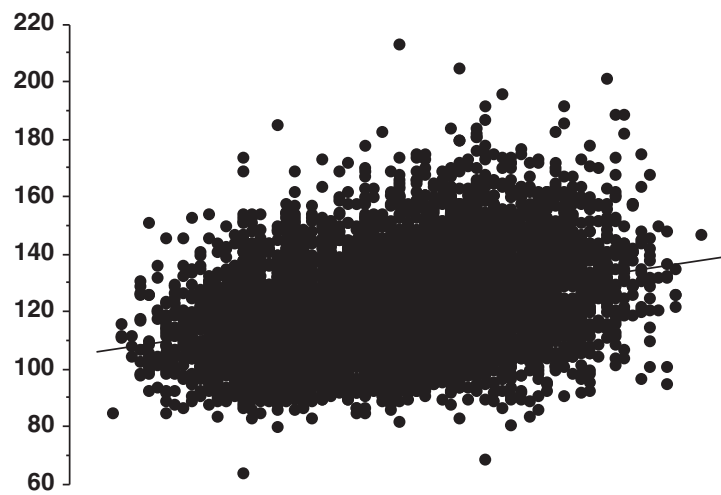

b Population B

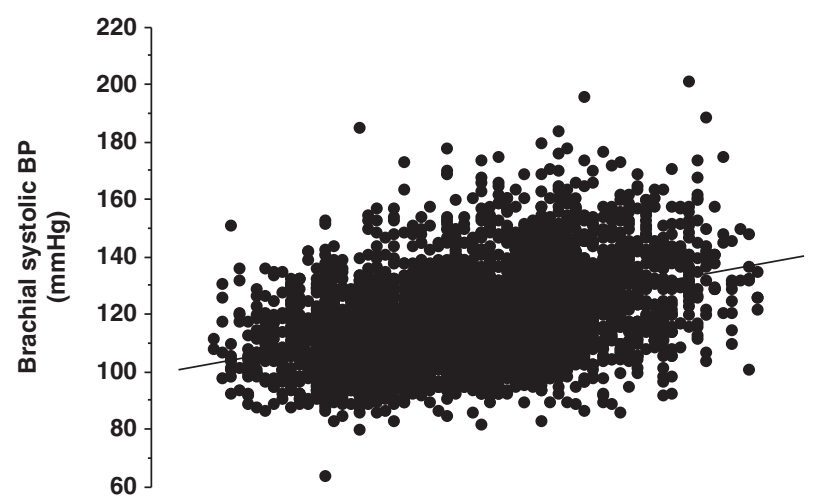

C Population C

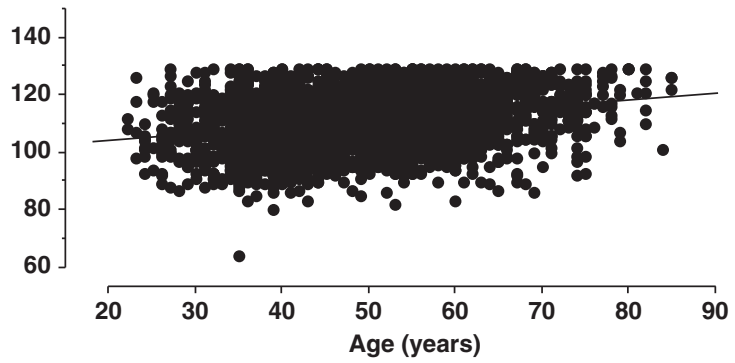

Figure 2 Relationship between age and brachial systolic blood pressure (BP) in (a) population A $(n=7348, r=0.329, P<0.0001)$, (b) population B $(n=3760, r=0.411, P<0.0001)$ and (c) population C $(n=2672$, $r=0.286, P<0.0001)$.

whereas there was no difference in subjects 20-29 years of age between central systolic BP and brachial systolic BP (population A, $P=0.24$; population $\mathrm{B}, P=0.22$; population $\mathrm{C}, P=0.97$; Tables 3 and 5 ).

Table 5 lists the mean and 2 s.d. of central systolic BP in each decade of age in populations A, B and C. Values of central systolic BP for individuals without major cardiovascular risk factors are listed in the column marked as 'population B' (Table 5), including those with hypertension determined by brachial BP. However, brachial BP is an established and independent cardiovascular risk factor, supporting the concept that individual risk stratification should be made taken into account both brachial and central BP. Central systolic BP was lowest in population $\mathrm{C}$ comprising subjects in the optimal and normal brachial BP categories (Table 5). 
Table 3 Brachial SBP in each age decade of populations A-C

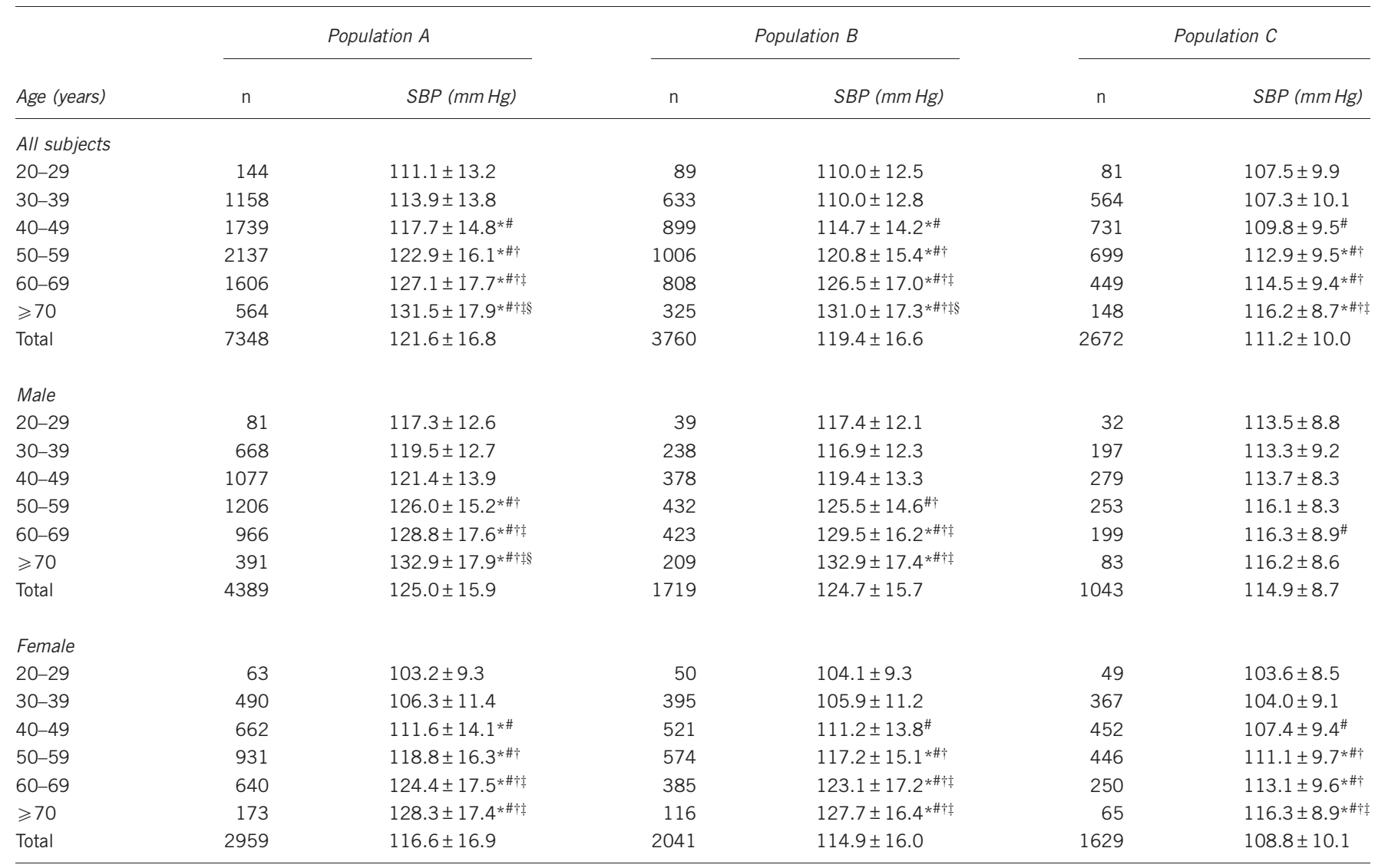

Abbreviations: Population A, subjects taking no medication for hypertension, dyslipidemia or diabetes mellitus; Population B, subjects without diabetes, dyslipidemia or current smoking and not taking antihypertensive medication; Population C, subjects with optimal or normal BP and no major cardiovascular risk factors; SBP, systolic blood pressure.

Values are mean \pm s.d.

Trend across age decades, $P<0.0001$ (analysis of variance (ANOVA)); ${ }^{*} P<0.01$ vs. $20-29$ years, ${ }^{\#} P<0.01$ vs. $30-39$ years, ${ }^{\star} P<0.01$ vs. $40-49$ years, ${ }^{\dagger} P<0.01$ vs. $50-59$ years, ${ }^{\S} P<0.01$ vs. 60-69 years (Scheffe's F-test).

Central systolic BP was closely correlated with brachial systolic BP (Figure 4) and, thus, was significantly different among subjects from different BP categories defined using brachial BP; central systolic BP was increased across the brachial $\mathrm{BP}$ categories in populations $\mathrm{A}, \mathrm{B}$ and $\mathrm{C}$ (Table 6).

\section{DISCUSSION}

Despite the general agreement that central BP bears a closer relationship to cardiovascular target organ damage and cardiovascular events than brachial $\mathrm{BP},^{7-11}$ its use in clinical practice has been limited because of the lack of reliable reference values. As direct measurement of central BP requires an invasive approach, several techniques for the noninvasive estimation of central BP have been developed..$^{7-11,14,15,18-22}$ Central BPs obtained using different devices, although yielding the same type of information, are not readily comparable between measurements, and each technique seems to require its own reference values as diagnostic thresholds. This study provided important information for considering reference values for central systolic BP estimated using the Omron device by investigating characteristics of these measurements in the Japanese general population. This may be an initial step in establishing central BP as a clinical tool in the diagnosis and management of hypertension and for individual risk evaluation.
Although numerous factors affect central BP, this study identified age and brachial BP as particularly important factors in investigating the distribution of central systolic BP values based on their significance of effect in univariate analysis. Presentation of reference values by age and brachial BP category would be a possible option for practical use, although not validated. Although the increase in central systolic BP with age could be largely attributed to the close relationship between central systolic BP and brachial systolic BP, the age-dependent increase was somewhat greater for central systolic BP than for brachial systolic BP. An age-dependent increase in aortic stiffness would cause premature return of the reflected waves in late systole, and thus an augmentation of central BP. ${ }^{24,25}$ This may be one of the reasons for the greater impact of age on central than on brachial BP. The age-dependent increase in central systolic BP may reflect age-dependent increase in the number and/or severity of cardiovascular risk factors in individuals. Indeed, most tested cardiovascular risk factors had a positive impact on central systolic BP. The impact of increasing age on central systolic BP was not prominent in population $\mathrm{C}$ and central systolic BP did not significantly increase with age in subjects aged $\geqslant 50$ years in this population, further supporting the considerable contribution of age-dependent increases in brachial systolic BP to those in central systolic BP. 
Table 4 Relationship between estimated central systolic blood pressure and other variables by univariate analysis

\begin{tabular}{|c|c|c|}
\hline Variables & Standardized coefficient & P-value \\
\hline Age (years) & 0.441 & $<0.0001$ \\
\hline Gender (male) & 0.115 & $<0.0001$ \\
\hline Body height $(\mathrm{cm})$ & -0.101 & $<0.0001$ \\
\hline Body weight (kg) & 0.104 & $<0.0001$ \\
\hline Body mass index $\left(\mathrm{kgm}^{-2}\right)$ & 0.218 & $<0.0001$ \\
\hline Waist circumference $(\mathrm{cm})$ & 0.253 & $<0.0001$ \\
\hline Systolic blood pressure (mm Hg) & 0.948 & $<0.0001$ \\
\hline Diastolic blood pressure $(\mathrm{mm} \mathrm{Hg})$ & 0.730 & $<0.0001$ \\
\hline Heart rate (b.p.m.) & 0.063 & $<0.0001$ \\
\hline Serum creatinine $\left(\mathrm{mg} \mathrm{dl}^{-1}\right)$ & 0.061 & $<0.0001$ \\
\hline eGFR $\left(\mathrm{ml} \mathrm{min}{ }^{-1}\right.$ per $\left.1.73 \mathrm{~m}^{-2}\right)$ & -0.143 & $<0.0001$ \\
\hline Uric acid $\left(\mathrm{mg} \mathrm{dl}^{-1}\right)$ & 0.137 & $<0.0001$ \\
\hline Fasting plasma glucose $\left(\mathrm{mg} \mathrm{dl}^{-1}\right)$ & 0.180 & $<0.0001$ \\
\hline LDL cholesterol $\left(\mathrm{mg} \mathrm{dl}^{-1}\right)$ & 0.096 & $<0.0001$ \\
\hline HDL cholesterol $\left(\mathrm{mg} \mathrm{dl}^{-1}\right)$ & -0.063 & $<0.0001$ \\
\hline Triglycerides $\left(\mathrm{mg} \mathrm{dl}^{-1}\right)$ & 0.140 & $<0.0001$ \\
\hline Hemoglobin $\left(\mathrm{gdl}^{-1}\right)$ & 0.104 & $<0.0001$ \\
\hline
\end{tabular}

Abbreviations: eGFR, estimated glomerular filtration rate; HDL, high-density lipoprotein; LDL, low-density lipoprotein.

The study subjects had no overt cardiovascular disease, although some were under medical treatment for hypertension, diabetes or dyslipidemia. Antihypertensive drugs differentially affect central $\mathrm{BP}, 7,26$ and antidiabetic and antidyslipidemic drugs may alter central BP through modification of arterial stiffness. Thus, subjects under such medication were first excluded from the study population (population A). In the next step of analysis, we investigated the effects of cardiovascular risk factors on central BP values. As previous studies demonstrated, central BP is an independent predictor of target organ damage and cardiovascular events, and a better marker in the management of hypertension than conventional brachial BP. ${ }^{7-12}$ Thus, population $\mathrm{B}$ was determined along the concept that central BP, but not brachial BP, should be used for risk evaluation. Subjects in this population had neither major cardiovascular risk factors (diabetes, dyslipidemia, smoking) other than hypertension (defined using brachial BP) nor antihypertensive medication. However, excluding subjects with diabetes, dyslipidemia and smoking from population A did not alter the subsequent value of central systolic BP in each age decade or brachial BP category (population B). This does not necessarily indicate that effects of cardiovascular risk factors on central BP are minimal. Indeed, central systolic BP was higher in subjects with hypertension, diabetes, dyslipidemia or smoking habit as compared with those without such cardiovascular risk factors in population A (data not shown). In this study, some subjects with diabetes or dyslipidemia, probably those with a moderate to severe condition, might have been taking relevant medications and, thus, were already excluded from population A. This may, at least partially, contribute to the similar central systolic BP values between populations A and B. Alternatively or additionally, the lack of data on some other cardiovascular risk factors such as family history may contribute to the results. Exclusion of overweight subjects (body mass index $>25 \mathrm{~kg} \mathrm{~m}^{-2}$ ) or those with metabolic syndrome from population B did not alter the results (data not shown). Although central BP may be superior to brachial BP, brachial BP is already established as an independent and strong predictor of cardiovascular
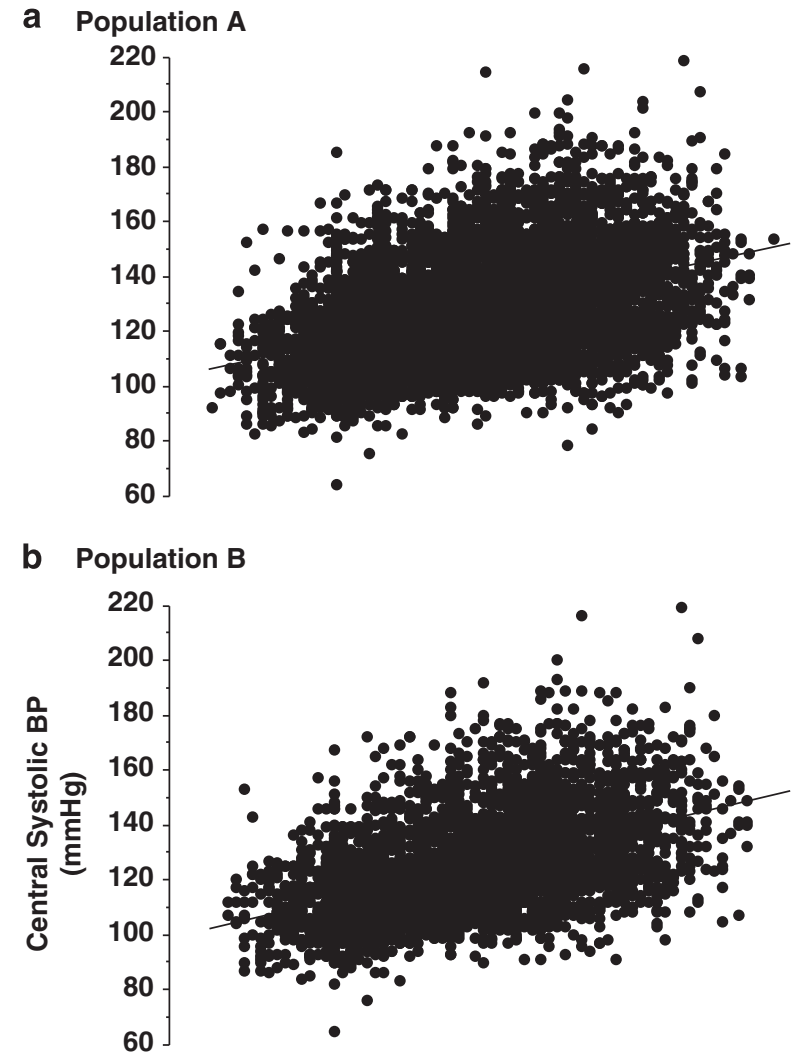

C Population C

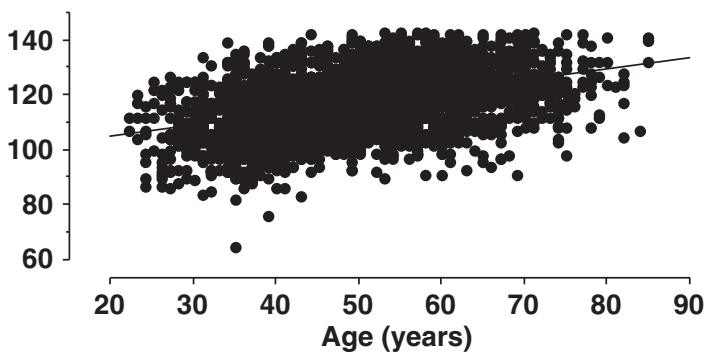

Figure 3 Relationship between age and central systolic blood pressure (BP) in (a) population $\mathrm{A}(n=7348, r=0.420, P<0.0001)$, (b) population $\mathrm{B}$ $(n=3760, \quad r=0.481, \quad P<0.0001)$ and (c) population $C \quad(n=2672$, $r=0.420, P<0.0001)$.

morbidity and mortality. ${ }^{1-6}$ Thus, subjects with hypertension based on brachial BP category should be excluded from populations used to investigate characteristics of central systolic BP in nearnormal subjects (without major risk factors). In line with this concept, population C consisted of subjects with optimal and normal brachial BP and no major cardiovascular risk factors. The values of central systolic $\mathrm{BP}$ in this population were lower than those in population $\mathrm{A}$ or $\mathrm{B}$, and the age-dependent increase in central systolic $\mathrm{BP}$ was smaller in population $\mathrm{C}$ than in population $\mathrm{A}$ or $\mathrm{B}$. Thus, a large part of the aging effects on central systolic BP disappeared after excluding subjects with increased brachial BP. Although normal values of central BP should be determined on the basis of the impact of central BP on cardiovascular mortality and morbidity in longitudinal studies, the distribution of central 
Table 5 Distribution of central systolic blood pressure values and late systolic pressure values in the radial artery (SBP2) in each age decade of populations $\mathrm{A}-\mathrm{C}$

Central systolic blood pressure ( $\mathrm{mm} \mathrm{Hg}$, mean \pm 2 s.d.)

\begin{tabular}{|c|c|c|c|c|c|c|}
\hline Age (years) & & \\
\hline All subjects & $n=7348$ & $n=3760$ & $n=2672$ & $n=7348$ & $n=3760$ & $n=2672$ \\
\hline $20-29$ & $109.6 \pm 27.0$ & $108.9 \pm 25.2$ & $107.5 \pm 22.2$ & $96.2 \pm 25.4$ & $95.5 \pm 23.7$ & $94.2 \pm 20.8$ \\
\hline $40-49$ & $122.8 \pm 31.6^{* \#}$ & $120.3 \pm 30.6^{* \#}$ & $115.2 \pm 20.8^{* \#}$ & $108.6 \pm 29.6$ *\# & $106.3 \pm 28.7$ *\# & $101.4 \pm 19.6^{* \#}$ \\
\hline $50-59$ & $130.9 \pm 34.2^{* \# \dagger}$ & $128.9 \pm 32.8^{* \# \dagger}$ & $120.8 \pm 20.9^{* \# \dagger}$ & $116.2 \pm 32.1^{\text {*\#† }}$ & $114.3 \pm 30.8^{\text {*\#† }}$ & $106.7 \pm 19.7^{\text {\#\# }}$ \\
\hline $60-69$ & $135.3 \pm 38.0^{\star \# \# \ddagger}$ & $134.7 \pm 37.4^{* \# \dagger \dagger}$ & $122.1 \pm 20.9^{* \# \dagger}$ & $120.3 \pm 35.7^{* \# \dagger \dagger}$ & $119.8 \pm 35.0^{* \# \dagger \dagger}$ & $108.0 \pm 19.7^{\text {\#\# }}$ \\
\hline Male & $n=4389$ & $n=1719$ & $n=1043$ & $n=4389$ & $n=1719$ & $n=1043$ \\
\hline $20-29$ & $112.6 \pm 30.4$ & $112.1 \pm 28.9$ & $109.6 \pm 24.4$ & $99.0 \pm 28.6$ & $98.5 \pm 27.3$ & $96.1 \pm 23.0$ \\
\hline 30-39 & $119.1 \pm 27.9$ & $115.7 \pm 26.4$ & $112.2 \pm 21.1$ & $105.1 \pm 26.2$ & $101.9 \pm 24.9$ & $98.6 \pm 19.8$ \\
\hline $40-49$ & $125.1 \pm 31.0 * \#$ & $122.6 \pm 29.7^{* \#}$ & $116.4 \pm 19.2^{* \#}$ & $110.8 \pm 29.1^{* \#}$ & $108.4 \pm 27.9^{* \#}$ & $102.6 \pm 18.0$ *\# \\
\hline Female & $n=2959$ & $n=2041$ & $n=1629$ & $n=2959$ & $n=2041$ & $n=1629$ \\
\hline $20-29$ & $105.7 \pm 19.6$ & $106.4 \pm 20.7$ & $106.1 \pm 20.4$ & $92.5 \pm 18.3$ & $93.2 \pm 19.4$ & $92.9 \pm 19.1$ \\
\hline 30-39 & $111.5 \pm 27.1$ & $110.8 \pm 26.4$ & $108.7 \pm 21.6$ & $98.0 \pm 25.4$ & $97.3 \pm 24.9$ & $95.3 \pm 20.3$ \\
\hline $40-49$ & $119.2 \pm 31.0 * \#$ & $118.6 \pm 30.7^{* \#}$ & $114.4 \pm 21.6^{* \#}$ & $105.2 \pm 29.1^{* \#}$ & $104.7 \pm 28.8^{* \#}$ & $100.7 \pm 20.4^{* \#}$ \\
\hline $50-59$ & $128.1 \pm 34.4^{* \# \dagger}$ & $126.6 \pm 32.4^{* \# \dagger}$ & $120.2 \pm 21.6^{* \# \dagger}$ & $113.6 \pm 32.4^{* \# \dagger}$ & $112.2 \pm 30.4^{* \# \dagger}$ & $106.2 \pm 20.3^{* \# \dagger}$ \\
\hline $60-69$ & $133.7 \pm 37.6^{* \# \dagger \dagger}$ & $132.2 \pm 37.1^{* \# \dagger \dagger}$ & $121.4 \pm 21.0^{* \# \dagger}$ & $118.8 \pm 35.3^{* \# \dagger \dagger}$ & $117.4 \pm 34.8^{* \# \dagger \dagger}$ & $107.3 \pm 19.7^{* \# \uparrow}$ \\
\hline$\geqslant 70$ & $137.3 \pm 37.5^{\star \# \dagger \dagger}$ & $136.9 \pm 35.6^{* \# \dagger \dagger}$ & $125.2 \pm 19.1^{* \# \dagger \dagger}$ & $122.2 \pm 35.3^{* \# \dagger \dagger}$ & $121.8 \pm 33.4^{* \# \dagger \dagger}$ & $110.8 \pm 18.0$ *\#+ \\
\hline Total & $124.6 \pm 37.4$ & $122.7 \pm 36.0$ & $116.0 \pm 23.9$ & $110.3 \pm 35.2$ & $108.4 \pm 33.8$ & $102.2 \pm 22.4$ \\
\hline
\end{tabular}

Abbreviations: Population A, subjects taking no medication for hypertension, dyslipidemia or diabetes mellitus; Population B, subjects without diabetes, dyslipidemia or current smoking and not taking antihypertensive medication; Population C, subjects with optimal or normal blood pressure and no major cardiovascular risk factors; SBP2, blood pressure corresponding to the second systolic peak of radial pulse waveform.

Values are mean \pm 2 s.d.

Trend across age decades, $P<0.0001$ (analysis of variance (ANOVA)); ${ }^{*} P<0.01$ vs. $20-29$ years, ${ }^{\sharp} P<0.01$ vs. $30-39$ years, ${ }^{\dagger} P<0.01$ vs. $40-49$ years, ${ }^{\dagger} P<0.01$ vs. $50-59$ years, ${ }^{\S} P<0.01$ vs. 60-69 years (Scheffe's F-test).

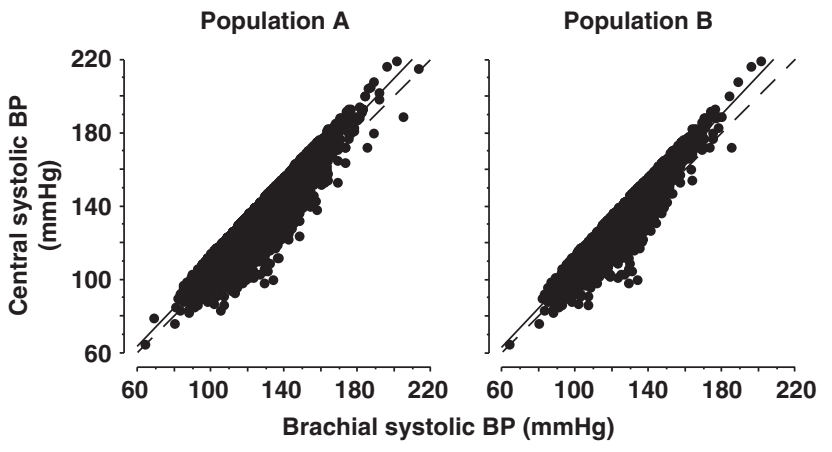

Figure 4 Relationship between central and brachial systolic blood pressure (BP) in population A (left panel; $n=7348, r=0.940, P<0.0001$ ) and population B (right panel; $n=3760, r=0.943, P<0.0001$ ). Lines of identity (dotted lines) and regression (solid lines) are shown.

$\mathrm{BP}$ values obtained in population $\mathrm{C}$ may provide important information for discussing the normal value.

Epidemiological and cohort studies have clearly shown that brachial systolic BP increases with advancing age. ${ }^{1-3}$ As for brachial
BP, however, classification of BP category is defined regardless of age in most hypertension guidelines, ${ }^{1-3}$ resulting in the majority of elderly population defined as having hypertension. A similar phenomenon is observed in the relationship between age and central systolic BP. Although we presented central systolic BP values in each age decade, this does not necessarily mean that the reference value of central systolic BP should be established in each age decade. As in the case for brachial BP, benefits from BP-lowering treatment in various ages and central systolic BP levels should be taken into consideration for future determinations of reference or normal values of central systolic BP. For the moment, in the clinical setting, central systolic BP may be assessed with age and brachial BP category taken into consideration, and then individual cardiovascular risk could be stratified by age, brachial BP and central systolic BP.

In this study, the characteristics of central systolic BP estimated by the Omron device were studied for the following reasons: (1) several devices based on different technologies are available for estimating central BP, and both reference and normal values need to be individually determined for each device; (2) central BP estimated by the SphygmoCor device is reported to be a better predictor of cardiovascular outcome than brachial $\mathrm{BP}^{7,9,14,15}$ and highly correlated with central BP estimated by the Omron device; ${ }^{19-21}$ (3) central 
Table 6 Distribution of central and brachial systolic blood pressure values in each brachial blood pressure category (BP category) of populations A-C

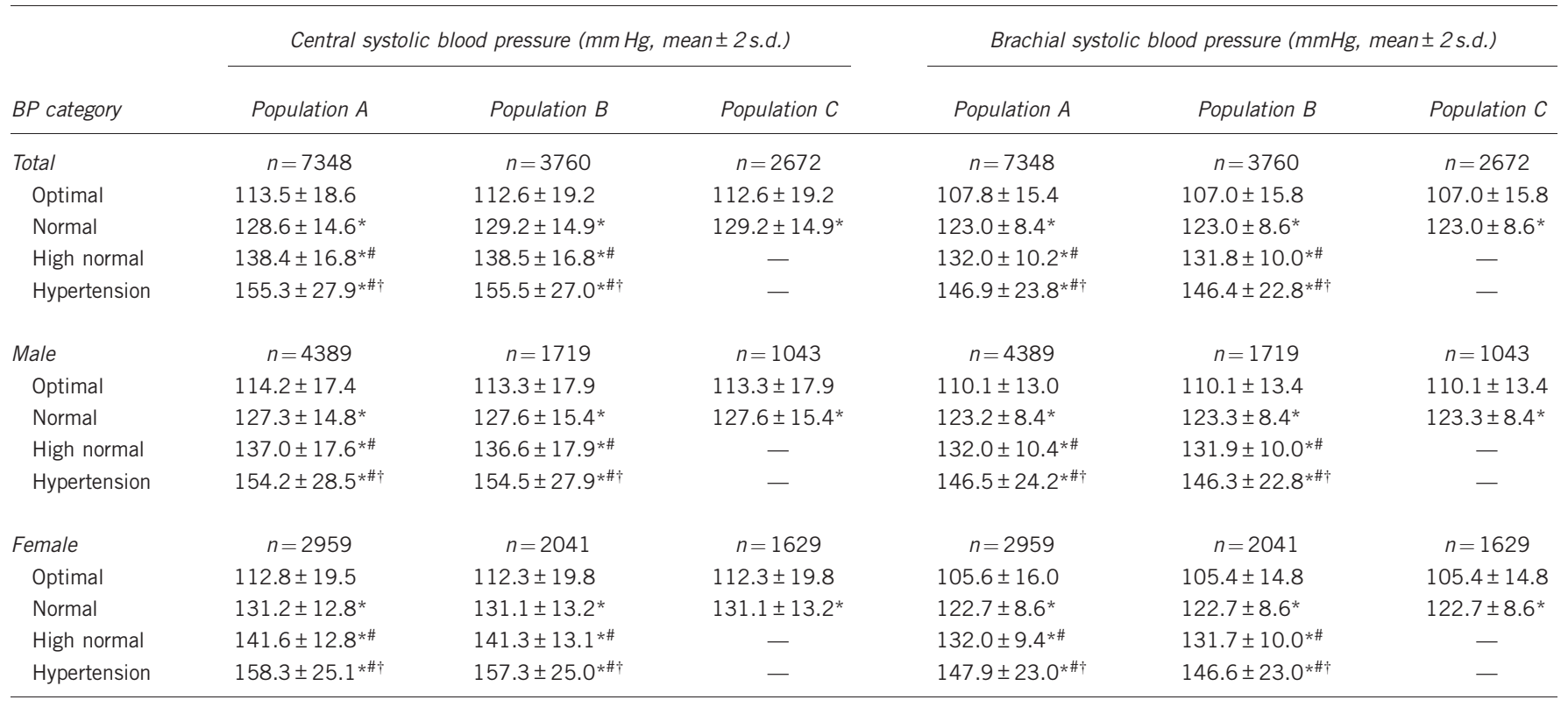

Abbreviations: Population A, subjects taking no medication for hypertension, dyslipidemia or diabetes mellitus; Population B, subjects without diabetes, dyslipidemia or current smoking and not taking antihypertensive medication; Population C, subjects with optimal or normal BP and no major cardiovascular risk factors.

taking antihypertensive medi
Values are mean \pm 2 s.d.

Trend across blood pressure categories, $P<0.0001$ (analysis of variance (ANOVA)); ${ }^{*} P<0.0001$ vs. optimal, ${ }^{\sharp} P<0.0001$ vs. normal, ${ }^{\dagger} P<0.0001$ vs. high normal (Scheffe's F-test).

systolic BP estimated by the Omron device is closely and linearly correlated with simultaneously and invasively measured central aortic pressure; $^{18,21,22}$ and (4) differences between invasively measured and noninvasively estimated central systolic BP are larger using the SphygmoCor device than using the Omron device. ${ }^{21}$ As the Omron device estimates central systolic BP in an automated manner, estimation of central systolic BP using this device is suitable for the clinical setting and is used widely spread in Japan, thus requiring reference values. Moreover, greater interindividual variability in central systolic BP than in brachial systolic BP throughout brachial $\mathrm{BP}$ categories observed in this study supports the clinical significance of the establishment of reference values for central BP besides those for brachial $\mathrm{BP}^{27}$

The potential limitations of this study include that this was a crosssectional study performed in a single institution and, at present, outcome data are not available. Second, although we provided the distribution of central BP values in each age decade, how to use these values in a clinical setting (diagnosis and management of hypertension) remains to be discussed. Third, central systolic BP was estimated only once in one subject and, thus, we could not exclude subjects with poor reproducibility of central systolic BP measurements. These points should be noted when interpreting the present data.

In conclusion, this study investigated the characteristics of central systolic BP estimated by the Omron technique and provided the distribution of these values. The present results contribute to individual risk stratification and make an important initial step in the implementation of central BP as a clinical tool in the diagnosis and management of hypertension.

\section{CONFLICT OF INTEREST}

The authors declare no conflict of interest.
1 Chobanian AV, Bakris GL, Black HR, Cushman WC, Green LA, Izzo Jr JL, Jones DW, Materson BJ, Oparil S, Wright Jr JT, Roccella EJ. Joint National Committee on Prevention, Detection, Evaluation, and Treatment of High Blood Pressure. National Heart, Lung, and Blood Institute; National High Blood Pressure Education Program Coordinating Committee. Seventh report of the Joint National Committee on Prevention, Detection, Evaluation, and Treatment of High Blood Pressure. Hypertension 2003; 42: 1206-1252.

2 Mancia G, De Backer G, Dominiczak A, Cifkova R, Fagard R, Germano G, Grassi G, Heagerty AM, Kjeldsen SE, Laurent S, Narkiewicz K, Ruilope L, Rynkiewicz A, Schmieder RE, Boudier HA, Zanchetti A, Vahanian A, Camm J, De Caterina R, Dean V, Dickstein K, Filippatos G, Funck-Brentano C, Hellemans I, Kristensen SD, McGregor K, Sechtem U, Silber S, Tendera M, Widimsky P, Zamorano JL, Erdine S, Kiowski W, Agabiti-Rosei E, Ambrosioni E, Lindholm LH, Viigimaa M, Adamopoulos S, AgabitiRosei E, Ambrosioni E, Bertomeu V, Clement D, Erdine S, Farsang C, Gaita D, Lip G, Mallion JM, Manolis AJ, Nilsson PM, O'Brien E, Ponikowski P, Redon J, Ruschitzka F, Tamargo J, van Zwieten P, Waeber B, Williams B. Management of Arterial Hypertension of the European Society of Hypertension; European Society of Cardiology. 2007 Guidelines for the Management of Arterial Hypertension: The Task Force for the Management of Arterial Hypertension of the European Society of Hypertension (ESH) and of the European Society of Cardiology (ESC). J Hypertens 2007; 25: 1105-1187.

3 Ogihara T, Kikuchi K, Matsuoka H, Fujita T, Higaki J, Horiuchi M, Imai Y, Imaizumi T, Ito S, Iwao H, Kario K, Kawano Y, Kim-Mitsuyama S, Kimura G, Matsubara H, Matsuura H, Naruse M, Saito I, Shimada K, Shimamoto K, Suzuki H, Takishita S, Tanahashi N, Tsuchihashi T, Uchiyama M, Ueda S, Ueshima H, Umemura S, Ishimitsu T, Rakugi H. Japanese Society of Hypertension Committee. The Japanese Society of Hypertension Guidelines for the Management of Hypertension (JSH 2009). Hypertens Res 2009. 32: 3-107.

4 Prospective Studies Collaboration. Age-specific relevance of usual BP to vascular mortality: a meta-analysis of individual data for one million adults in 61 prospective studies. Lancet 2002; 360: 1903-1913.

5 Blood Pressure Lowering Treatment Trialists' Collaboration. Effects of different bloodpressure-lowering regimens on major cardiovascular events: results of prospectivelydesigned overviews of randomised trials. Lancet 2003; 362: 1527-1535.

6 Sairenchi T, Iso H, Irie F, Fukasawa N, Yamagishi K, Kanashiki M, Saito Y, Ota H, Nose T. Age-specific relationship between blood pressure and the risk of total and cardiovascular mortality in Japanese men and women. Hypertens Res 2005; 28: 901-909.

7 Williams B, Lacy PS, Thom SM, Cruickshank K, Stanton A, Collier D, Hughes AD, Thurston H, O'Rourke M. CAFE Investigators; Anglo-Scandinavian Cardiac Outcomes Trial Investigators; CAFE Steering Committee and Writing Committee. Differential impact of blood pressure-lowering drugs on central aortic pressure and clinical 
outcomes: principal results of the Conduit Artery Function Evaluation (CAFE) study. Circulation 2006; 113: 1213-1225

8 Agabiti-Rosei E, Mancia G, O'Rourke MF, Roman MJ, Safar ME, Smulyan H, Wang JG, Wilkinson IB, Williams B, Vlachopoulos C. Central blood pressure measurements and antihypertensive therapy: a consensus document. Hypertension 2007; 50: 154-160.

9 Roman MJ, Devereux RB, Kizer JR, Lee ET, Galloway JM, Ali T, Umans JG, Howard BV. Central pressure more strongly relates to vascular disease and outcome than does brachial pressure: the Strong Heart Study. Hypertension 2007; 50: 197-203.

10 Wang KL, Cheng HM, Chuang SY, Spurgeon HA, Ting CT, Lakatta EG, Yin FC, Chou P, Chen $\mathrm{CH}$. Central or peripheral systolic or pulse pressure: which best relates to target organs and future mortality? J Hypertens 2009; 27: 461-467.

11 Williams B, Lacy PS. Central aortic pressure and clinical outcomes. J Hypertens 2009; 27: 1123-1125.

12 Vlachopoulos C, Aznaouridis K, O'Rourke MF, Safar ME, Baou K, Stefanadis C Prediction of cardiovascular events and all-cause mortality with central haemodynamics: a systematic review and meta-analysis. Eur Heart J 2010; 31: 1865-1871.

13 Neisius U, Bilo G, Taurino C, McClure JD, Schneider MP, Kawecka-Jaszcz K, StolarzSkrzypek K, Klima $Ł$, Staessen JA, Kuznetsova T, Redon J, Martinez F, Rosei EA, Muiesan ML, Melander O, Zannad F, Rossignol P, Laurent S, Collin C, Lonati L, Zanchetti A, Dominiczak AF, Delles C. Association of central and peripheral pulse pressure with intermediate cardiovascular phenoytpes. J Hypertens 2012; 30: 67-74.

14 de Luca N, Asmar RG, London GM, O'Rourke MF, Safar ME. REASON Project Investigators. Selective reduction of cardiac mass and central blood pressure on lowdose combination perindopril/indapamide in hypertensive subjects. J Hypertens 2004; 22: $1623-1630$.

15 Wang KL, Cheng HM, Sung SH, Chuang SY, Li CH, Spurgeon HA, Ting CT, Najjar SS, Lakatta EG, Yin FC, Chou $\mathrm{P}$, Chen $\mathrm{CH}$. Wave reflection and arterial stiffness in the prediction of 15-year all-cause and cardiovascular mortalities: a community-based study. Hypertension 2010; 55: 799-805.

16 Pauca AL, O'Rourke MF, Kon ND. Prospective evaluation of a method for estimating ascending aortic pressure from the radial artery pressure waveform. Hypertension 2001; 38: 932-937.

17 Gallagher D, Adji A, O'Rourke MF. Validation of the transfer function technique for generating central from peripheral upper limb pressure waveform. Am J Hypertens 2004; 17: 1059-1067.
18 Takazawa K, Kobayashi H, Shindo N, Tanaka N, Yamashina A. Relationship between radial and central arterial pulse wave and evaluation of central aortic pressure using the radial arterial pulse wave. Hypertens Res 2007; 30: 219-228.

19 Richardson CJ, Maki-Petaja KM, McDonnell BJ, Hickson SS, Wilkinson IB, McEniery $\mathrm{CM}$. Comparison of estimates of central systolic blood pressure and peripheral augmentation index obtained from the Omron HEM-9000Al and SphygmoCor systems. Artery Res 2009; 3: 24-31.

20 Kips JG, Schutte AE, Vermeersch SJ, Huisman HW, Van Rooyen JM, Glyn MC, Fourie $\mathrm{CM}$, Malan L, Schutte R, Van Bortel LM, Segers P. Comparison of central pressure estimates obtained from SphygmoCor, Omron HEM-9000Al and carotid applanation tonometry. J Hypertens 2011; 29: 1115-1120.

21 Ding FH, Fan WX, Zhang RY, Zhang Q, Li Y, Wang JG. Validation of the noninvasive assessment of central blood pressure by the SphygmoCor and Omron devices against the invasive catheter measurement. Am J Hypertens 2011; 24: 1306-1311.

22 Takazawa K, Kobayashi H, Kojima I, Aizawa A, Kinoh M, Sugo Y, Shimizu M, Miyawaki Y, Tanaka N, Yamashina A, Avolio A. Estimation of central aortic systolic pressure using late systolic inflection of radial artery pulse and its application to vasodilator therapy. J Hypertens 2012; 30: 908-916.

23 Matsuo S, Imai E, Horio M, Yasuda Y, Tomita K, Nitta K, Yamagata K, Tomino Y, Yokoyama $\mathrm{H}$, Hishida A. Collaborators developing the Japanese equation for estimated GFR. Revised equations for estimated GFR from serum creatinine in Japan. Am J Kidney Dis 2009; 53: 982-992.

24 Liao D, Arnett DK, Tyroler HA, Riley WA, Chambless LE, Szklo M, Heiss G. Arterial stiffness and the development of hypertension. The ARIC study. Hypertension 1999; 34: 201-206.

25 Edwards DG, Gauthier AL, Hayman MA, Lang JT, Kenefick RW. Acute effects of cold exposure on central aortic wave reflection. J Appl Physiol 2006; 100: 1210-1214.

26 Matsui Y, Eguchi K, O'Rourke MF, Ishikawa J, Miyashita H, Shimada K, Kario K. Differential effects between a calcium channel blocker and a diuretic when used in combination with angiotensin II receptor blocker on central aortic pressure in hypertensive patients. Hypertension 2009; 54: 716-723.

27 McEniery CM, Yasmin, McDonnell B, Munnery M, Wallace SM, Rowe CV, Cockcroft JR, Wilkinson IB. Anglo-Cardiff Collaborative Trial Investigators. Central pressure: variability and impact of cardiovascular risk factors: the Anglo-Cardiff Collaborative Trial II. Hypertension 2008; 51: 1476-1482. 